\title{
Jovens e adultos do campo: educação, passado e futuro
}

\author{
Rural youth and adults: education, past and future
}

\author{
Alessandro Augusto de Azevêdo \\ Universidade Federal do Rio Grande do Norte
}

Resumo

fenômeno da baixa escolarização entre jovens e adultos que vivem no campo não é definível apenas no contexto dos índices estatísticos, mas como expressão de um conjunto amplo de processos vivenciados pelos sujeitos em suas respectivas infâncias e adolescências, sob contextos históricos de exclusão. Essas vivências, apropriadas pelos sujeitos, alimentam suas memórias e conformam suas representações sociais, na imersão das quais se torna possível a compreensão de fatores que organizam o tipo de relação que esses sujeitos estabelecem com a educação escolar. Assim, evidenciamos algumas histórias, num exercício do dimensionamento da memória como fator de modelação das representações sociais (MOSCOVICl, 1978) de determinados sujeitos, jovens e adultos trabalhadores rurais, em torno de determinado objeto, a educação escolar. Nessa perspectiva metodológica de rememoração de experiências (LARROSA, 1994; KENSKI, 1994), a educação escolar é um componente que atravessa a relação que os sujeitos jovens e adultos do campo estabelecem com seu passado e suas perspectivas de futuro, construções concretas e simbólicas que se entremeiam com o cotidiano, ditando suas respectivas imersões no mundo.

Palavras-chave: Jovens e adultos. Trabalhadores rurais. Educação.

\section{Abstract}

The phenomenon of low education among youth and adults living in the countryside is not definable only in the context of statistical indexes, but as the expression of a broad set of processes experienced by the subjects in their childhood and youth, in historical contexts of exclusion. These experiences, by appropriate subject, feed their memories and shape their social representations, the immersion of which makes it possible to understand the factors that organize the kind of relationship that these subjects have with the school education. Thus, we highlight some stories, an exercise of memory as the scaling factor modeling of social representations (MOSCOVICl, 1978) of certain subjects, young adults and rural workers, around a given object, school education. In this methodological perspective of remembering experiences (LARROSA, 1994; KENSKI, 1994), the education as a component that traverses the relationship that rural young and adult subjects establish with their past and their future prospects, concrete and symbolic buildings that are intertwined with daily life, dictating their respective immersions in the world.

Keywords: Youth and adults. Rural workers. Education. 
Tá fechano sete tempo

Qui mia vida é camiá

Pulas istrada no mundo

Dia e noite sem pará

Ajuntei no isquicimento

O qui o baldono guardô meus meste a istrada e o vento

Quem na vida me insinô Vô me alembrano na viage

Das pinura qui passei

Daquelas dura parage

Nos lugari adonde andei

O dia não amanheceu direito. $\bigcirc$ sol tenta espalhar em degradé um tapete de luz para aplacar a escuridão opressora da madrugada. Seus raios vão irrompendo e alterando a coloração de pedaços do céu enquanto anuncia à família do pequeno Damião que mais um dia de peleja os aguarda. Um fenômeno rotineiro para todos.

Naquele instante, o mesmo acontece com outras crianças que Damião nem conhece ou sonha que existam. Pitiu, Rita e Arlindo em São Tomé. Genário em Serrinha e Eduardo, em Santana do Matos. Maria Lúcia em Lages, Ana em Goianinha, Cícero em Ceará-Mirim e Pedro Barreto da Silva, em Santa Fé. E tantas outras crianças filhas de trabalhadores rurais, espalhados pelo sertão do Rio Grande do Norte.

Ao sair para a roça junto com os seus pais, cada um deles não imagina que dali a quarenta anos estarão se encontrando para, juntos, participar de um processo de luta pela terra que redundará na conquista da Fazenda Modelo. Não imaginam que o futuro de cada um se porá lado a lado, diante de arames que cercam uma área de latifúndio, numa outra madrugada como aquela, em outro lugar.

Naquele momento, todo o futuro daquelas crianças era o que o pai oferecia: o cabo da enxada, da foice, do machado ou da xibanca. Não conheciam a história da estrutura fundiária brasileira que os condenavam àquela situação. Não sabiam onde ficava o Mato Grande, a região que décadas mais tarde, acolheria seus desejos de terem um pedaço de 
terra para o trabalho, a produção e a sobrevivência familiar. Não sabiam calcular quantos anos levariam para que essa necessidade deixasse de ser um sonho desesperançado e se tornasse realidade ao alcance de suas mãos e pés. Sequer sabiam como escrever isso tudo - se assim desejassem - numa carta a ser enviada a amigos mais próximos ou ao Presidente da República.

Sabiam que nesse mundo existia um lugar - denominado Escola - destinado a crianças como elas, para aprenderem habilidades relacionadas a ler, escrever e contar. Intuíam - porque os mais velhos assim diziam - que se demonstrassem inteligência, interesse e esforço próprios, poderiam alcançar até a quarta série e aí (quem sabe?) teriam a oportunidade de alimentar um futuro diferente daquele que o destino (ou Deus) havia reservado para os seus antepassados e que para eles se revestiam de um presente sofrido.

Mas a escola (e suas possíveis conquistas) sempre foi vista como um lugar distante para a maioria dessas pessoas, como resultado de um processo histórico de exclusão das populações do campo a bens simbólicos e materiais básicos. Assim, em 2010, enquanto o analfabetismo, entre potiguares com mais de 5 anos residentes na zona urbana, atingia 16, 1\%, segundo o IBGE (BRASIL, 2010), entre a população do campo, esse índice alcançava $31,9 \%$.

Mais do que um possível roteiro de um filme, essas histórias pessoais se revelaram como uma dimensão da compreensão das representações sociais que assentados de reforma agrária tinham da educação escolar objeto de minha pesquisa no assentamento Modelo II, em João Câmara, Rio Grande do Norte?. Ouvir essas histórias me conduziu ao vislumbre do peso que um passado de exclusão, distância ou negação da escola exerce sobre os sujeitos no contexto de sua produção representacional em torno de um determinado objeto socialmente valorizado e, ao mesmo tempo, tão inacessível. A cada história contada, parecia-me cada vez mais acertado o mergulho nesse cotidiano temporalmente distante, como condição para o entendimento das relações que estabelecem hoje com a educação escolar.

Com o presente trabalho, proponho-me evidenciamos algumas histórias, num exercício do dimensionamento da memória como fator de modelação das representações sociais (MOSCOVICl, 1978) de determinados sujeitos, jovens e adultos trabalhadores rurais, em torno de determinado 
objeto, a educação escolar. No estudo das representações sociais desses sujeitos sobre a educação escolar não poderia deixar de olhar com cuidado para todo o período anterior à sua chegada ao assentamento ${ }^{2}$ e ao conteúdo desse percurso que cada um trilhou, especialmente naqueles episódios em que a referência à escola e seus produtos los saberes, as experiências de aprendizagem e as possibilidades de melhoria de vida que ela promete) se fazem presentes.

\section{A memória como dimensão da construção da realidade}

Algumas tardes e muitas noites emolduraram minhas conversas com os assentados da Agrovila Santa Luzia (uma das duas agrovilas do Assentamento Modelo) onde pudemos rememorar suas respectivas trajetórias, desde a infância até a chegada no assentamento. Havia a clareza de que, nessa rememoração, emergiriam narrativas prenhes de "reconstruções" que os próprios sujeitos fazem desses fatos a partir das suas respectivas leituras de mundo, tal como nos alerta Larrosa (1994, p. 48), de que "[...] o sentido do que somos depende das histórias que contamos e das que contamos a nós mesmos [...], em particular das construções narrativas nas quais cada um de nós é, ao 210 mesmo tempo, o autor, o narrador e o personagem principal."

Isso significa dizer que a memória não opera como uma caixa onde se guardam os fatos vividos em seu estado "puro" e estanque, mas como um processo de construção que comporta e está atravessado por uma diversidade de influências e necessidades do presente. Aquilo que se narra é uma reconceitualização do passado desde um olhar que reside no presente. (KENSKI, 1994). Ou seja, uma determinada focalização do passado, num processo de rememoração de alguns de seus aspectos mais significativos, representa uma descrição contemporânea dele. Está prenhe de uma determinada representação da realidade e, portanto, traz, no seu ventre, significados e reinterpretações.

Nesse sentido, ainda que sejam as pessoas que se lembram, suas memórias são atravessadas por marcos simbólicos e tramas de caráter sociocultural que modelam a interpretação das narrativas rememoradas. Assim, o que é lembrado do passado está sempre mesclado com aquilo que se sabe sobre ele e com a avaliação que se faz dele. Mais ainda: as memórias, muitas vezes, adquirem uma qualidade que Morin (2000) atribui às crenças e às ideias, de não apenas se constituírem em produtos das nossas mentes, mas também serem entidades mentais que têm vida e poder, podendo, assim, possuir-nos. 
Atravessar o matagal das narrativas dos sujeitos implicou, portanto, descortinar suas memórias enquanto elementos integrantes do processo de formação das suas representações sociais, denominado por Moscovici (1978) como ancoragem, na medida em que compõem o conjunto de conhecimentos preexistentes em face dos quais as experiências novas se erguem e com os quais dialogam ou, eventualmente, se digladiam. Aliás, - poder criador da atividade representativa reside exatamente na capacidade dos sujeitos em manipular o repertório de saberes e experiências acumuladas em sua vida (seja deslocando-os e combinando-os, seja integrando-os ou desintegrando-os).

Nesse mar de cognições que são as memórias processadas pelos sujeitos, a literatura em representações sociais tem reconhecido sua importância como dimensão do contexto da produção representacional. A abordagem estrutural (teoria do núcleo central), formulada por JeanClaude Abric e defendida por Sá (2002), por exemplo, ao pressupor que toda representação se organiza em torno de sistema central - composto de cognições com mais elevada resistência a processos de mudança - e um sistema periférico - composto de cognições flexíveis, mais abertas a mudanças de contextos - localiza no primeiro a presença característica da memória coletiva e da história do grupo.

Essas memórias não são apenas "lembranças", registros fugidios que dão apoio a um argumento, a percepções do cotidiano ou a uma visão de mundo. Elas, também, se entranham no mundo real como conhecimento prévio que molda práticas sociais e se mantém nas interações como traços culturais. Adubam a chamada experiência dóxica do mundo, o interminável processo em que os sujeitos apreendem o mundo social, suas divisões arbitrárias e as tramas tecidas a partir daí, dando-lhes um reconhecimento de legitimação. Com isso, alimentam os esquemas de percepção, de pensamento e de ação que orientam os indivíduos, assegurando-lhes a conformidade e a constância de determinadas práticas ao longo do tempo. (BOURDIEU, 2002). A esse propósito lembra Domingos Sobrinho:

[...] a construção das representações não se dá [...] num vazio social. Elas são construídas por sujeitos que ocupam uma determinada posição no espaço social sendo, por conseguinte, portadores de 'sistemas de disposições duráveis, estruturas estruturadas predispostas a funcionarem como estruturas predispostas 
a funcionarem como estruturas estruturantes'[...]. $\bigcirc$ habitus é, portanto, [...] uma dimensão fundamental a ser apreendida no processo de construção das representações sociais, sobretudo, quando se trata de compreender as particularidades que envolvem as diferentes 'leituras' de objetos socialmente compartilhados [...]. (DOMINGOS SOBRINHO, 2000, p. 11 19-120).

Discutindo as relações entre as representações sociais, a educação e os processos do aprender, Madeira (2000) argumenta que uma representação social traz consigo uma história que é, também, a história particular dos sujeitos. Segundo ela,

Uma representação social é a particularização, num objeto, do processo mais amplo de apreensão e de apropriação do real pelo homem, enquanto sujeito-agente situado. É tanto a síntese possível a um dado sujeito, num determinado tempo e espaço, de um processo no qual ele, em sua totalidade, está envolvido, quanto leva as marcas da inserção deste mesmo sujeito numa totalidade social determinada. A representação social traz em si a história, na história particular de cada um. Nas variâncias de sua estruturação estão as particularidades de cada sujeito e, em suas invariâncias, as marcas do sentido atribuído, por determinados segmentos ou grupos ou, até, por sua totalidade, a um dado objeto. (MADEIRA, 2000, p. 241 ).

Assim, no cerne das representações está uma dimensão fundamental que se organiza em torno de uma memória experiencial ou rememorações: um processo de autoconsciência que participa não, apenas, da formação das personalidades, mas também das construções identitárias, das subjetivações de caráter histórico.

Assim, na história particular de cada um dos sujeitos da agrovila Santa Luzia, perpassa outra que lhes ultrapassa como individualidades: a história da educação escolar partejada no meio rural brasileiro e potiguar. Nessa, mais ampla, a Escola já existia antes deles. Mas a possibilidade do direito a frequentá-la era algo tão distante quanto havia sido para os seus pais e avós. Não obstante ausente em seu cotidiano, a escola mantinha sua aura de referência fundamental como mecanismo por excelência da conquista de status e prestígio social. 
Tratava-se, ademais, da reprodução de um imaginário talhado pelas promessas iluministas e modernistas acerca do poder redentor da escola e da educação obrigatória. E alimentado por uma visão debitária do otimismo rousseauniano - de que as possibilidades naturais humanas, na medida em que acolhidas pela educação, não seriam desvirtuadas pela sociedade - e do pensamento psicológico moderno. Segundo este último, a partir de uma ajuda externa - seja na forma de um apoio ou como ausência de impedimentos - os sujeitos alcançariam diversos graus de plenitude em variadas funções, capacidades e habilidades de sua personalidade. (SACRISTÁN, 2001).

Mas essa promessa modernista, iluminista e burguesa, aprisionada em seu formalismo, aparecia como inalcançável aos desejos dos pequenos personagens que apresentei nos parágrafos anteriores nem da aguda leitura da realidade, feita pelos seus respectivos pais, que constatava a impossibilidade do exercício do direito à educação dadas as condições objetivas em que estavam imersos.

Que condições inexistentes eram essas? As mesmas enumeradas pelo próprio Sacristán:

exercício do direito à educação, transformado em obrigação pela maioria dos Estados, não é cumprido pelo simples fato de sua enunciação [...]. Exige condições materiais que o tornem realidade: a) que seja possível o acesso material a uma vaga na escola, garantia que compete ao Estado assegurar. Os estados costumam aceitar o direito em suas legislações antes de prever as condições necessárias para exercê-lo; b) possibilidade de assistir regularmente às aulas e permanecer na escola durante a etapa considerada como obrigatória, sem obstáculos provenientes das condições de vida exteriores ou das práticas escolares internas que possam levar à exclusão ou à evasão escolar; c) possibilidade de prescindir do trabalho infantil para que se possam praticar as duas condições anteriores. (SACRISTÁN, 2001, p. 19-20).

Os pais de Damião, Maria Lúcia, Rita, Cícero e da maioria dos assentados com quem conversei não se sentiram na obrigação de explicar essas questões aos seus filhos. Nem poderiam. A sobrevivência da família thes gritava, diariamente, ao ouvido com a inclemente quentura do sol sobre suas cabeças e o furor das raras trovoadas anunciadoras de inverno. Precisavam buscar o que comer. No mato. Em terras alheias. Tal como aprenderam com os seus pais e os pais dos seus pais e os pais dos pais dos seus pais... 


\section{Memórias da exclusão da escola e da itinerância Severina}

Seu Eduardo, sentado num banquinho de madeira, observa atentamente quando organizo o equipamento de gravação, ponho a microfita dentro do pequeno gravador. Ele registra nunca ter visto um daquele tamanhinho e pergunta se já pode falar. Cruza as pernas devagar e olha para um ponto distante, que eu não alcanço. Parece ser desse ponto que vão surgindo as imagens da narração que ele inicia e me apresenta como se abrisse a janela da sua infância.

Eu nunca estudei...no meu tempo...eu era menino com sete ano, ficava com um caquim de enxada, no mato, limpando pedacim de maniva, pedacim de roça... a mãe mais as tia mandava: "meu fi, traga ali dois balde de roça!". Lá ia a gente arrancar, ela às vez ia mais a gente. Chegava em casa ia rapar, relar, num ralim...e suspender pa fazer beijú...pa comer, de manhã. (Seu Eduardo Marcelino dos Santos, 2004)

Quando Seu Pedro Barreto da Silva chega para conversar comigo, o sol já está se deitando no horizonte. Ele ajeita o chapéu na cabeça. Suas roupas e sua pele têm o cheiro e a cor de quem acaba de chegar do trabalho na roça. É a mistura do seu suor com a quentura do sol e da terra. Ele se desculpa pelos trajes e começa a falar sem muita hesitação. As palavras parecem dançar na sua boca de poucos dentes, enquanto a fumaça do bule de café dança pela cozinha sob a do fogão de lenha.

Nós morava num lugar, por nome Santa Fé, era deste tamanhinho. Aí meu pai era um homem que nunca gostou de rua. Nunca. Logo o seguinte: ele tomava uma cana muito grande e ele pra se estranhar com um era bem fácil. Aí nós morava nesse lugar, nessa ruinha chamada Santa Fé...nós fomo morar num tabuleiro, só tinha mato. Era aqui...nessas terra aqui, Brejinho, Santo Antonio do Salto da Onça, era pra ali. Lá a gente só escutava o berro da raposa. Era eu, Maria, Francisco e Mané, nós tudim... moramo... quando amanhecia o dia, era cada um da gente, a minha irmã mais mamãe. [...] Aí pronto, ia buscar água, com bem uma légua na cabeça, um potim na cabeça... bem uma légua...e eu mais papai mais os outo ia pra mata. (Seu Pedro Barreto da Silva, 2004). 
A infância vivida por esses sujeitos não foi diferente da maioria das crianças em idade escolar que vivia na zona rural potiguar há quarenta, cinquenta, anos. Ela se processava atrelada à dinâmica migratória ou de precária permanência das suas famílias.

Essa itinerância (ou precária permanência) era uma condição resultante do que alguns autores (SIGAUD, 1977, GARCIA JR., 1983) denominam de "o fim da terra de permissão", isto é, uma mudança nas relações de trabalho pela qual os trabalhadores rurais e suas respectivas famílias perdem a permissão para morar e colocar seus roçados no interior das fazendas para se transformarem em um trabalhador clandestino. Aliás, conforme nos mostra Silva (1996), foi essa situação que ensejou, especialmente a partir da década de 1950, a emergência de vários conflitos de terra no Rio Grande do Norte e o consequente surgimento do movimento sindical rural.

Apesar dos autores especializados localizarem o fim da "terra de permissão" por volta da década de 1950 e 1960 lquando os trabalhadores - com o apoio decisivo da lgreja Católica - criam seus primeiros sindicatos no Rio Grande do Norte), os depoimentos dos sujeitos de nosso trabalho indicam a permanência dessas relações de trabalho por todo um período posterior. Uma temporalidade que engloba, inclusive, os anos imediatamente anteriores às ocupações que espocaram no Mato Grande durante a década de 1990. Se essa permanência se dava de uma forma marginal ou preponderante no contexto das relações de trabalho na região, é uma questão a ser investigada em outro momento, já que não é objeto deste trabalho.

Em seu depoimento, Seu Pedro Barreto da Silva, por exemplo, deixa clara essa sua condição momentos antes de participar do processo de conquista da terra.

Todo ano eu botava um roçadim na propriedade do seu Vavá, que hoje é o prefeito de João Câmara... todo ano ele dava, pra quem quisesse. [...] Num cobrava nada, apenas a forrage. Se o caba possuísse um bichinho, ele num se importava que a pessoa tirasse um tanto quanto po bicho... mas agora o que eu achava rim era porque sempre que prantava uma batata, uma fava, num dava pa colher, porque quando chegava época de botar o gado podia ter o que tivesse, ele botava por cima. (Seu Pedro Barreto, 2004). 
Uma realidade não diferente do seu tempo de criança, quando ao seu pai cabia a responsabilidade de reunir a família para plantar e colher para a garantia da sobrevivência de todos, em terras alheias. Esse imperativo obrigava crianças e adultos envolverem-se nas tarefas da roça e, consequentemente, retirava dos primeiros (e em certa medida também dos segundos) o tempo para frequentarem a escola.

Como nos contam Seu Marcelino e Seu Pedro Barreto, na infância que vivenciaram o tempo não era apropriado para ir à escola estudar, mas para se meter por dentro da capoeira, destocando mato, arrancando feijão, espigas de milho ou catando mandioca para, depois, fazer os beijus ${ }^{3}$ que esconderiam a fome por algumas horas ou dias. Essa dinâmica era uma constante por todas as suas vidas. Espraiou-se, acompanhando suas respectivas passagens pela adolescência, assistindo a seus primeiros namoros e seus casamentos, determinando-os a passar distante da escola no seu permanente caminho para a roça.

Para outros, não havia escola por perto. A mobilidade da família às voltas com a busca pela sobrevivência agia no sentido de perpetuar a distância da escola porque o tempo de permanência numa fazenda ou em qualquer 216 outro lugar coincidia com a presença mais ou menos demorada do inverno ou de outras oportunidades de trabalho precário. Terminado um "serviço" na terra de alguém, chegava a hora de a família se retirar e ir de encontro ao caminho da incerteza, alguns centímetros logo após a porteira da fazenda.

Pela estrada, a busca esperançosa por melhores dias esbarrava numa constatação: a fartura parecia se esconder por detrás do horizonte à espera de ser trazida pelas nuvens anunciadoras de inverno. Restavam os eventuais encontros com outras famílias parceiras de infortúnio, perambulando de fazenda em fazenda ou em direção à cidade - à "rua" - em busca de oportunidades para aliviar o "perrengue" de não se ter comida, trabalho ou perspectiva. Escola?

Nesse tempo não se falava, o que aparecia era umas escolhinhas particular. Aí nesse tempo ninguém ligava pra isso não. Eu digo isso porque, se tinha escola não era para filho de pobre não. [...] Porque nesse meu tempo, filho de pobre não estudava, porque a gente morava ali no Matão, [...] da Assunção pra baixo. Fui numa escola assim, particular, pequenininha, por pouco tempo, que acabou-se não foi para frente. Porque não existia esse negócio de escola não. (Seu Raimundo Rosa, 2005). 
Tinha não. Logo o seguinte: quando [pai] saiu de lá [...], de onde nós morava, viemo pa Ceará Mirim. A bagagem da gente, era de papai, era tão grande que vinha num jumento... toda a bagagem da gente vei num jumento...A gente de pé e papai amontado...a gente criança, de pé, e papai amontado...aqui e acolá tomando uma cana, vez e outa, uma lapada de cana e chicote. Aí fiquemo num lugar por nome - Jorge, terra do doutor Varela...eu só sei que quando eu saí do Jorge saí com 16 ano...e lá num tinha nada de escola lá a não ser em Ceará Mirim mermo... Mais também num via ninguém... Aî também num ia, né? Aí saí de lá e fui prum lugar por nome Ramada... dento de lelmo Marinho. E lá também num tinha escola. Tinha na rua. E eu fui trabaiando, trabaiando, trabaiei doze ano. Aí pra lá eu decidi me casar e... até hoje... (Seu Pedro Barreto Da Silva, 2004).

A escola e os seus produtos - a educação escolar, os conhecimentos e habilidades que ela propiciava e a certificação que formalizava social e institucionalmente o estágio de aprendizado alcançado pelos sujeitos - apareciam tão episódicos e incertos, para esses sujeitos, como o inverno.

[...] era pouco...estudava um mês... dois mês...quinze dias... porque era dificulidade de professor. Porque nesse tempo, quando eu era pequena, no meu tempo de estudo, aí era difícil um professor. Tinha um professor aqui, ia ter longe...às vez a gente tava num lugar distante, às veze, assim, na época de seca, precisava se mudar, assim, devido às criação...procurar ficar num canto mai melhor pra gente ficar... aí lá tinha um professor, estudava ali uns dia, depois voltava novamente, aí num estudava mais. (Dona Maria Lúcia Pereira Monteiro, 2005).

Estudar era fruto de um acaso, uma sorte, uma chance oferecida pela eventual existência de uma escola próxima de onde se estava morando - com toda a provisoriedade que esse morar the apresentava, já que o tempo de residência estava umbilicalmente ligado ao tempo de oferta de trabalho e oportunidades de sobrevivência familiar. E exatamente pelo imperativo do trabalho, o tempo de se ir estudar estava subordinado ao tempo do trabalho. 
Olhando para trás, alguns assentados registram que a educação escolar os alcançava, seja na forma de uma unidade escolar instalada perto de onde estavam morando ou pela vinda de um professor contratado para o trabalho de alfabetização das crianças da comunidade. Mas, em ambas as situações, apontam que, pelo fato dos professores morarem longe, "na rua", inexistia um processo de ensino e aprendizagem regular, permanente. Desse modo, os depoimentos demonstram que a memória desses sujeitos guardou a ida a uma sala de aula para estudar como uma prática episódica.

[Estudei] até a primeira [série]. [Não continuei] porque eu saí da escola. Meu pai foi-se embora. Aí eu não fui mais. Eu ia todo dia. O dia que a professora não ia, eu não ia também. Eu ia todo dia de manhã, mas um dia a professora vinha, outro dia não vinha... (Dona Maria Conceição Melo - "Dona Branca", 2005)

[Estudei] até a quarta. Consegui aqui no assentamento. Antes já tinha estudado, mas era um mês, quinze dias [...]. Porque era a quantidade de professor. Porque nesse tempo, quando eu era pequena, no meu tempo de estudar, aí era difícil ter um professor. Tinha, mas era longe, era distante [...]. Não tinha lugar para a gente ficar. Aí era um professor. Aí quando era no outro dia não tava mais. Era de um terreno para outro. Aí professor era difícil. (Dona Maria Lúcia Pereira Monteiro, 2005).

Em face dessas condições, não admira que, para os pais desses trabalhadores rurais, não havia futuro outro que não aquele oriundo da labuta diária com o cabo da enxada, o cabo da foice ou o cabo do machado, instrumentos mais próximos e palpáveis para se garantir futuro aos filhos do que os bancos escolares, cadernos e lápis. Assim ocorreu, entre outros, com Seu Damião de Melo que me afirmou, mostrando as mãos enrugadas e calejadas como provas da afirmação seguinte: "A primeira coisa que meu pai me deu foi cabo da enxada, cabo de foice, cabo de machado. [... Meu pai não queria que eu fosse [à escola]. [... . Dizia que tinha futuro era o cabo da enxada. Foi o que eu aprendi.

Vários são, portanto, os parâmetros pelos quais podemos medir a distância desses homens e mulheres para com a escola. Alguns deles revelam o abandono dos poderes públicos para com a promoção da educação da população do campo - a exemplo do que acontece na área de saúde, cultura, esporte e lazer. Na comunidade onde nasceram e cresceram não se dispunha 
de uma escola (ou de um prédio escolar) que thes servissem. Precisavam andar léguas. Alguns outros apontam como principal fator a própria condição de precisarem ajudar na sobrevivência da sua família, desde a mais tenra idade, com sua capacidade de trabalho.

E há, por fim, as indicações do pouco estímulo dos pais, numa época quando a lonjura da escola representava um obstáculo mais do que suficiente para que a necessidade de envolver os filhos na labuta da roça desestimulasse pais em perseguir um destino - ver o filho frequentando regularmente a escola - que se configurava a dezenas de quilômetros sociais. O desestímulo para com a educação escolar era alimentado por uma convicção fatalista de que poucas eram as chances de seus filhos terem um destino social diferente do que eles tiveram, por obra e graça da escola.

Aprofundando contatos, cruzando conversas e ampliando escutas, não é improvável o encontro com trajetórias em que todos os elementos acima se combinam, ao longo do tempo, ocupando pesos e momentos diferenciados. Assim, juntos, eu e eles, tentamos (re)tecer a colcha-história de suas respectivas vidas, até onde podíamos.

\section{Retecendo retalhos da colcha-história dos homens e mulheres da agrovila Santa Luzia}

Na condição de "moradores de favor" na terra de algum latifundiário, ou como trabalhadores precários, essas famílias davam suor e uma boa parte do seu tempo para sua própria manutenção e outra parte para o dono das terras. Somavam-se àquela massa humana cuja exclusão dos direitos básicos de cidadania era aprofundada como efeito da perspectiva faústica. (BERMAN, $1986)^{4}$ de modernização urbano-industrial que tomou conta do país e orientou os projetos das elites governamentais brasileiras desde princípios da década de 1950.

Assim, nas memórias dos assentados da agrovila Santa Luzia estão inscritas as vivências das "baixas", produzidas pela conjugação trágica entre desenvolvimento urbano, abandono de populações do campo à margem de direitos e legitimação das estruturas de manutenção do latifúndio.

O acesso a essas memórias, em parte, foi possível através das entrevistas, conversas informais e dos grupos de discussão. Outra parte delas caiu 
em minhas mãos quando, em casa, enveredei-me em sistematizar as palavras vocalizadas na aplicação do teste de associação livre. Nele, fiz uso da expressão "passado" como palavra indutora e solicitei que cada entrevistado fornecesse outras três palavras que estivessem a ela associadas. Depois, pedi que justificassem o porquê de cada uma.

No processo de interpretação, dei prioridade àquelas palavras ou expressões que foram evocadas em primeiro lugar, dado que, em várias entrevistas, algumas das expressões seguintes apenas serviam para explicar de maneira mais ou menos sintética a que foi dita no início do teste.

Frente à pergunta sobre o passado antes da chegada ao assentamento, os sujeitos elencaram substantivos, adjetivos e expressões que, como retalhos, compõem a colcha-história particular-coletiva de cada um, tal como a personagem Tita, do romance "Como água para chocolate" (1995), de Laura Esquivel, que tecia numa colcha as tristezas que acumulava ao longo da vida.

A solicitação de referências léxicas acerca do passado anteriormente à chegada no assentamento, inevitavelmente, conduzia as respostas dos sujeitos no sentido de estabelecer comparações entre o passado e o presente. Assim, o papel crucial da conquista do assentamento - que para mim era,

220 apenas, uma hipótese - se configurou como realidade na força das palavras evocadas e das justificações apresentadas, por mais simplórias que pareçam.

$\bigcirc$ conjunto de respostas que me foi fornecido está organizado no quadro abaixo segundo a ordem de evocação lou seja, se, após a pergunta indutora, a expressão/palavra foi a primeira, a segunda ou a terceira a ser vocalizada) e a quantidade de vezes em que ela foi apresentada, pelos 31 (trinta e um) sujeito que participaram do teste.

Reuni os retalhos que me foram fornecidos pelos assentados e fui recompondo a colcha-história dos homens e mulheres da agrovila Santa Luzia, separando e agrupando cada retalho (ou "unidade semântica") segundo a familiaridade que tinham em termos de cor e/ou textura (uma "unidade significativa"), conformando um determinado conjunto expressivo ou "temas". Assim, no corpo do quadro abaixo, as evocações são marcadas por cores. Cada uma delas se associa a uma temática: as expressões marcadas em verde compõem o grupo de evocações com as quais os sujeitos adjetivaram o passado negativamente. Já as expressões marcadas em laranja compõem as evocações com as quais os sujeitos apresentaram os traços mais marcantes de suas vidas 
nesse passado rememorado. E, por fim, nas expressões marcadas em azul, as evocações que indicam os sentimentos de frustração e arrependimento de alguns sujeitos, quanto às suas respectivas vidas, atualmente, quando comparadas com a vida que tinham no passado.

Quadro 1

"O seu passado antes de chegar no assentamento"

\begin{tabular}{|c|c|c|c|c|}
\hline \multirow{2}{*}{ Unidade Semântica } & \multicolumn{3}{|c|}{ Ordem de evocação } & \multirow{2}{*}{$\begin{array}{c}\text { Frequência da } \\
\text { evocação }\end{array}$} \\
\hline & I & $\|$ & III & \\
\hline Sofrimento & 2 & 2 & & 4 \\
\hline Ruim & 2 & 1 & & 3 \\
\hline Desemprego & 1 & 1 & 1 & 3 \\
\hline Não tinha terra & & 1 & 2 & 3 \\
\hline Era melhor & 2 & & & 2 \\
\hline Não criava animais & 1 & 1 & & 2 \\
\hline Não tinha casa & 1 & 1 & & 2 \\
\hline Apanhar castanha & & 2 & & 2 \\
\hline Tranqüilidade saúde & & 2 & & 2 \\
\hline Viver de ajudas & & 1 & 1 & 2 \\
\hline Dançar & 1 & & & 1 \\
\hline Trabalho em fábrica & 1 & & & 1 \\
\hline Trabalho & 1 & & & 1 \\
\hline Costura e lavagem de roupa & 1 & & & 1 \\
\hline Facilidade de ganhar dinheiro & 1 & & & 1 \\
\hline Na cidade tinha o que queria & 1 & & & 1 \\
\hline Bom, sem casamento & 1 & & & 1 \\
\hline Pagava renda ao dono da terra & 1 & & & 1 \\
\hline Mãe & 1 & & & 1 \\
\hline Luta & 1 & & & 1 \\
\hline Desassossego & 1 & & & 1 \\
\hline Andar pelo mundo & 1 & & & 1 \\
\hline
\end{tabular}




\begin{tabular}{|c|c|c|c|c|}
\hline \multirow{2}{*}{ Unidade Semântica } & \multicolumn{3}{|c|}{ Ordem de evocação } & \multirow{2}{*}{$\begin{array}{c}\text { Frequência da } \\
\text { evocação }\end{array}$} \\
\hline & I & $\|$ & III & \\
\hline Não foi bom & 1 & & & 1 \\
\hline Trabalho na fazenda & 1 & & & 1 \\
\hline Tristeza & 1 & & & 1 \\
\hline Difícil & 1 & & & 1 \\
\hline Complicado & 1 & & & 1 \\
\hline $\begin{array}{l}\text { Expulsão do acampamento pela } \\
\text { polícia }\end{array}$ & 1 & & & 1 \\
\hline Trabalho na educação & 1 & & & 1 \\
\hline Era outra pessoa & 1 & & & 1 \\
\hline Alegre & & 1 & & 1 \\
\hline Fazia música & & 1 & & 1 \\
\hline Biscates & & 1 & & 1 \\
\hline Divertimento & & 1 & & 1 \\
\hline Não devia a ninguém & & 1 & & 1 \\
\hline Fazer arupema & & 1 & & 1 \\
\hline $\begin{array}{l}\text { Na cidade não tinha dificuldade } \\
\text { em arranjar trabalho }\end{array}$ & & 1 & & 1 \\
\hline Liberdade de ir à festas & & 1 & & 1 \\
\hline Não tinha transporte & & 1 & & 1 \\
\hline Preocupação & & 1 & & 1 \\
\hline Não faltava emprego & & 1 & & 1 \\
\hline Casa dos pais & & 1 & & 1 \\
\hline Jogar bola & & 1 & & 1 \\
\hline Sofrimento mãe doente & & 1 & & 1 \\
\hline $\begin{array}{l}\text { Tinha casa própria (a atual é do } \\
\text { INCRA) }\end{array}$ & & 1 & & 1 \\
\hline Não tinha nada em casa & & 1 & & 1 \\
\hline Trabalho doméstico & & & 1 & 1 \\
\hline Limpar mato & & & 1 & 1 \\
\hline
\end{tabular}




\begin{tabular}{|l|c|c|c|c|}
\hline \multirow{2}{*}{ Unidade Semântica } & \multicolumn{2}{|c|}{ Ordem de evocação } & \multirow{2}{*}{$\begin{array}{c}\text { Frequência da } \\
\text { evocação }\end{array}$} \\
\cline { 2 - 5 } & \multicolumn{1}{|c|}{ I } & $\|$ & III & 1 \\
\hline Sustentar a família & & & 1 & 1 \\
\hline Pobreza & & & 1 & 1 \\
\hline As coisas eram melhores & & & 1 & 1 \\
\hline $\begin{array}{l}\text { Amizades "verdadeiras" (no as- } \\
\text { sentamento são "falsas") }\end{array}$ & & & 1 & 1 \\
\hline Faltava água & & & 1 & 1 \\
\hline Doença dos filhos & & & 1 & 1 \\
\hline Ocupava outros assentamentos & & & 1 & 1 \\
\hline Dificuldade & & & 1 & 1 \\
\hline Informação sobre MST & & & 1 & 1 \\
\hline Andar de bicicleta & & & 1 & 1 \\
\hline Era solteira & & & 1 & 1 \\
\hline O que precisava tinha em casa & & & 1 & 75 \\
\hline TOTAL & 29 & 28 & 18 & 18 \\
\hline
\end{tabular}

Obs.: duas pessoas não esponderam

\section{Dramas do desenraizamento}

A observação do Quadro acima nos revela um primeiro conjunto de unidades semânticas pelas quais os assentados sintetizam a vida anterior à chegada ao assentamento num período do qual não sentem saudades nem desejam retornar. Entre as palavras apresentadas em primeira evocação as que mais aparecem são "sofrimento" e "ruim", acompanhadas de perto pelas referências à desemprego e o não ter terra, elementos fundantes da condição de trabalhador.

drama do desenraizamento operado pela itinerância permanente é o tema preponderante, a marca que lhes atravessa a existência. Um drama carregado de incertezas e sofrimento - substantivos cujos conteúdos não desaparecem com a chegada ao assentamento, mas se mantém como uma tônica na vida de todos e de cada um. A conquista da terra, para os assentados que 
vocalizaram esses retalhos, põe termo a uma trajetória de muita instabilidade e de dor pela presença do não ter: não ter terra, não ter casa, não ter animais para criar... não ter referências.

Desse modo, não obstante haver ainda incertezas e sofrimentos também no atual contexto do assentamento, o que desaparece com a conquista da terra é uma determinada condição de enfrentamento do sofrimento e do drama do desenraizamento. Ter a terra, o lote para o cultivo do básico para a sobrevivência, e a própria moradia, se inserem como uma conquista inalienável da família e condição primária para a refundação do presente e do futuro de todos, portanto, condição de ressocialização e reenraizamento.

Rapaz, ante da ocupação eu morava alugado. [...] Arrependo não. Se eu tivesse me arrependido eu já tinha ido me embora. Tem que ir levando a vida aqui mermo, até o resto da minha vida eu vou levar minha vida aqui mermo. [...] Eu acho bom aqui porque o caba apronta, tem um lugar pra plantar, não tem aborrecimento do caba dizer 'não...vamos tirar o que tem dento que eu vou botar os bicho'....corre tudo direitim... (SEU MANOEL CÍCERO BANDEIRA, 2004).

A conquista da terra encerra um longo capítulo da história desses sujeitos, que, desde crianças até a maturidade, não conheceram outra rotina diferente da itinerância severina à procura de novas oportunidades que thes garantissem a sobrevivência de si e da sua família, seja a que deixou para trás, seja a que constituíram, ambas quando se tornaram adultos.

Se eu for dizer tudo o que eu já fiz...trabaiar em cana, trabaiar em usina, em salina, trabaiei em usina de algodão e findei aqui, tudo isso serviço braçal, só no interior e tamo aqui, durante o tempo que eu cheguei aqui e tem de trabaiar mais e trabaiar menos... (SEU EDUARDO MARCELINO DOS SANTOS, 2004).

Como os severinos do poema de João Cabral de Mello Neto, os sujeitos da agrovila Santa Luzia teceram suas respectivas trajetórias anteriores ao episódio da ocupação e conquista da terra, na base de migrações alimentadas pela fuga da pobreza e a esperança de melhores dias. Como contrapartida, dispunham somente da capacidade de trabalhar. Trabalho braçal e precário, na terra "dos outo", onde nunca se perguntava se estudavam, 
qual os seus respectivos graus de escolaridade. Onde eram thes negados direitos trabalhistas básicos e vivenciavam a humilhação de terem seus roçados devastados para a terra servir de pasto para o gado do dono da propriedade.

Home! uns tinha uma casinha veia de taipa, uns de tijolo, mas não tinha um pedacinho de roçado pra trabaiar. Aí trabaiavam na terra de um e de outo... a terra era alugada...trabaiava alugado com os patrão. É...quando achava um dia de serviço trabaiava, quando a gente queria prantar pedia um pedacinho de terra po patrão. Ele dava, mas as veze, quando antes da gente colher, ele sortava os bicho dento. Aí tudo isso acontecia. (DONA RITA FERNANDES DA SILVA, 2005).

Essa relação de permanente provisoriedade nas terras "dos ôuto" é a síntese do estado de itinerância desses sujeitos desenraizados que viviam "no mei do mundo", como costumam definir. Em tal situação, a possibilidade de conquista de terra - e, portanto, de ter um chão onde se enraizar e ter condições de, minimamente, sustentar a familia - se lhes apresentava como a conquista de outra permanência. Não a permanência da itinerância, mas a permanência do assentamento, de um presente e futuro refundados a partir da conquista da terra.

\section{Quando a conquista da terra não elimina saudades da vida anterior}

Outro conjunto, bem menos frequente, de evocações presentes no Quadro anteriormente mostrado situa o passado como um período cuja instabilidade econômica e precariedade social é sempre relativizada pela maior facilidade que os sujeitos tinham de, na cidade, arranjarem um emprego, ganharem dinheiro, de "ter o que queria"... Nesses casos, o processo de participação na conquista do assentamento adquire uma aura de uma aventura da qual os sujeitos se arrependem.

Observando o Quadro acima, vemos que algumas evocações apontam os elementos pelos quais o período anterior à chegada ao assentamento se configura como melhor do que o período anterior. Entre eles, os assentados se referem ao fato de que anteriormente não tinham dívidas - ao contrário de hoje em dia em que se veem às voltas com dívidas contraídas junto aos bancos 
para financiamento de projetos produtivos de viabilidade incerta - e que na cidade tinham mais facilidade em arranjar uma ocupação e, consequentemente, uma renda garantida.

Seu Manoel Rodrigues, Seu João Gabriel e Dona Damiana baixavam - olhar para o chão empoeirado da sala e demonstravam na curvatura dos ombros o cansaço de uma aposta em que se dão por perdedores.

Minha vida era melhor. Eu vivia na minha casa. Aqui nada é meu. Preste atenção: isso aqui é tudo do INCRA. Mas antes tudo o que eu precisava eu tinha em casa... no assentamento, no começo, a conversa é bonita! Se chegasse tudo em dia, era bom... onde eu habitava era melhor...era fartura...eu tinha pra dar, eu tinha pra vender... (SEU MANOEL RODRIGUES, 2004).

Meu marido é quem tem vez que diz: 'eu vou mimbora! Vou mimbora, puiquê num dá certo aqui!' [...] Ele diz que num tem silviço, uma hora tá trabaiando, outa hora tá parado, e fica aperreado puiquê o negócio dele é só trabaiar, trabaiar, somente. (Dona DAMIANA DAMIÃO DA SIIVA, 2005).

Quando eu trabaiava pa o doutor Arnô, [...] eu tinha o dinheiro da minha feira toda semana. Certo. E aqui as coisa é difícil. A situação no assentamento tá difícil... ganho o caba num tem, as coisa aqui num tá brincadeira não... (SEU JOÃO MARIA GABRIEL, 2005).

Em torno da noção de que "a vida anteriormente era melhor", articulam-se as explicações de que quando viviam na cidade, mesmo que enfrentando dificuldades, os sujeitos tinham mais oportunidades de superação dos seus problemas e mais facilidades para conseguir o necessário para sobrevivência de si e da família. Assim, ao mesmo tempo que a condição de mobilidade permanente se revela como consequência da precariedade instituída como padrão de vida, ela constituía, também, a condição da liberdade de buscar alternativas de trabalho.

Mas há um elemento presente no início dessas duas falas que é bastante significativo de que o processo de ocupação de terra envolve sujeitos que, apesar de estarem aparentemente num mesmo lugar social, não se colocam na mesma perspectiva, nem no momento da ocupação, nem posteriormente, quando da aventura de se construir o assentamento e refundar suas vidas. Esse elemento é a condição de "ter uma casa", ausente nas falas dos sujeitos que não se arrependem de terem lutado pelo assentamento e presente nas falas dos arrependidos. 
De fato, para os primeiros, a chegada ao assentamento, para quem não tinha onde morar ou morava "de favor" (mesmo que em casa de algum familiar), representou uma aposta de quase nenhuma perda, mas exclusivamente de ganhos, especialmente o primeiro deles: uma casa para morar.

Já para os segundos, o fato de já terem uma casa antes do processo de ocupação e conquista da terra, Ihes dava uma segurança para quem a aventura da luta pela terra somente se tornava vantajosa na medida em que representasse uma ampliação de suas possibilidades de trabalho e renda que, mesmo precariamente, já tinham se acostumado a conviver. Aos seus olhos, a vida sem perspectivas de melhoria que o assentamento oferece pode nem diferir das perspectivas que tinham antes, mas, pelo menos, a casa onde moravam era uma propriedade inalienável deles e não do Incra, como expressa Seu Manoel Rodrigues.

Esse conflito expressa bem (e em parte corrobora) a discussão que faz Martins (2003) acerca de que a morada esteja no centro das motivações e aspirações de acampados e assentados, constituindo o referencial de seu imaginário e de suas formulações utópicas. Sua presença no universo discursivo dos sujeitos, referenciada como uma ausência decorrente das migrações, seja como um bem que se perdeu no contexto da conquista do assentamento, é bastante representativa do significado que ela adquire como parâmetro das demandas que organizam as estratégias de sobrevivência e ponto de (re)aglutinação da família e agregados num novo contexło de (res)socialização.

A morada é porto seguro que estrutura - junto com o trabalho - o vivencial dos sujeitos, não apenas no momento quando ocorre a conquista da terra, mas em todo o processo que lhe é anterior, o da itinerância severina "sorto no mei do mundo, nas terra dos ôto". A conquista da morada, aliada à conquista da terra, se coloca como elementos primeiros na escala hierárquica de urgências próprias do vivencial desses sujeitos.

Para esse grupo de entrevistados que já tinha uma morada antes da conquista da terra, a vinda para o assentamento trouxe um duplo dilema: ao trocar o lugar onde moravam antes pelo assentamento, esses indivíduos assumiram uma perspectiva que se revelou problemática, pois passaram a morar numa casa que, oficialmente, não é deles (porque é do Incra) e trabalhar numa terra sem algumas condições ou garantias mínimas de rentabilidade. 


\section{A labuta na roça: passado, presente, futuro e código ético}

Atravessando os dois conjuntos de evocações oriundas da palavra indutora Passado, estão 22 evocações que se reportam ao universo do trabalho ou aos efeitos de sua ausência. Como as frequências se mostraram muito fragmentadas em torno dessa pergunta, a análise não pode se basear em termos da maior ou menor frequência das evocações, mas em termos das características de um determinado conjunto semântico e sua qualidade enquanto instância sintetizadora e evidenciadora de um tema presente nas indicações fornecidas pelos sujeitos.

Nesse sentido, um conjunto de evocações nos oferece um passado cujo recheio é a rotina de trabalho braçal, tanto de homens como de mulheres. Nessa unidade temática, os registros semânticos expressam, não apenas, o tipo de ocupação que desempenhavam ("trabalho na fazenda", "apanhar castanha", "limpar mato", "trabalho doméstico", "trabalho em fábrica", "lavagem e costura de roupa", "pagava renda ao dono da terra" e "biscates") mas também as condições em que viviam decorrentes da natureza precária do trabalho l"viver de ajudas", "não tinha terra", "não tinha casa", "não tinha nada em 228 casa", "sustentar a família").

Desse modo, pela efetividade da presença ou da ausência, o trabalho é cercado de um estado de onisciência na vida dos sujeitos. Delimita os rumos das trajetórias pessoais, as escolhas ou a falta delas. Inspira, inclusive, um código ético a partir do qual alguns assentados classificam os demais entre os que são "trabalhador" e os que não são, dado a maior ou menor empenho em manter o lote cultivado, com ou sem chuvas. Assume, portanto, um caráter de valor afetivo e simbólico, tal como também encontrado por Brandão (1999).

Essa classificação simples - "muito trabalhador" /"pouco trabalhador" - não poucas vezes, se faz presente nas assembleias e rodas de conversas entre assentados, marginando os debates, oferecendo parâmetros de maior ou menor aceitação de determinados projetos produtivos que se esboçam, seja por iniciativas de organizações não governamentais ou de instituições oficiais.

Seu Pitiu, quando se lembra do início do processo de conquista da terra, no período do acampamento conduz sua narração no sentido de comparar o que se poderia chamar de "espírito empreendedor" de alguns dos assentados, naquele momento seminal e atualmente. E acaba por localiza uma 
mudança de conduta de alguns deles, cujas razões remete a esse código ético fundado no trabalho.

É isso que eu quero dizer a você... [...] Naquela época, o caba mostrava tomém que era trabalhador, disposto, viu? E agora é bem pouco que é disposto ao roçado. Tem uns que tem roçado aí que nunca arrancou nem um toco. [...] Eu fico munto triste quando o caba diz que o assentamento não presta. Eu não queria nem repetir essa palavra, mas eu vou repetir pra completar a frase, mas eu vou repetir: quando o caba disser que não presta o assentamento, quem não presta é a pessoa, que a pessoa não é organizada. (FRANCISCO DE ASSIS SILVA - SEU PITIU, 2005).

Esse código ético é alimentado não, apenas, pelo olhar retrospectivo e avaliador das pelejas cotidianas que desenham a sua trajetória desde a tenra infância até os dias atuais, mas também pelas novas esperanças e oportunidades oferecidas pelo assentamento enquanto realidade fundante de um novo tempo e de uma nova condição de vida, a partir do qual as famílias passam a se recompor.

A chegada ao assentamento, desde um processo penoso consubstanciado em três despejos, adquiriu um sentido de recomposição de famílias desenraizadas e de superação da condição de mobilidade permanente que desenhava as trajetórias pessoais. A conquista da terra, assim, instituía uma nova perspectiva de futuro: as andanças severinas de anos de trabalho precário pareciam estar condenadas a se transformar em trabalho produtivo garantidor da própria subsistência sem a presença do patrão.

A presença da escola, nessas andanças, é experienciada e povoa as memórias dos sujeitos como uma ausência ou distância que, por um lado, referencia o passado que os condena à condição de "rudes" (como muitos se autodefinem) e, ao mesmo tempo, sopra como uma leve brisa a possibilidade de um futuro que se volta não à mudança dessa condição para si mesmos, mas se projeta como horizonte para as gerações de crianças, adolescentes e jovens. A escola não tem futuro para si - "rude" forjado pela labuta na roça quando sem terra - mas para a nova geração, desprovida (pelo menos em princípio) dessa obrigação, em razão da conquista da terra.

Nesse ponto, a conquista do direito à terra pelos adultos "rudes" torna-se a inflexão para a conquista do direito à escola pela geração seguinte, 
plasmada na possibilidade de não serem obrigados a repetir a trajetória da geração anterior e, portanto, não serem sujeitos portadores das mesmas memórias, nem do mesmo passado.

\section{Notas}

$1 \bigcirc$ Assentamento Modelo localiza-se no município de João Câmara, no Rio Grande do Norte, numa região comumente denominada de Mato Grande. A comunidade vive numa área de baixa precipitação pluviométrica, cujos membros não participam de um projeto coletivo de produção. Desenvolve uma produção à base da cultura agropecuária tradicional familiar, cujo volume raramente gera algum excedente que não seja utilizado para o mero reforço da reprodução da força de trabalho. Dotada de uma pequena unidade escolar, disposta em duas salas de aula, onde funcionam duas turmas de Ensino Fundamental $\left(1^{a}\right.$ a $4^{a}$ séries $)$ e, eventualmente, à noite, turmas de Educação de Jovens e Adultos.

2 O assentamento Modelo é o resultado de um processo de conquista da terra que se iniciou em 24 de agosto de 1994, quando cerca de 150 famílias ocuparam a Fazenda do Sr. Arnaud Júnior Câmara. Foram nove meses de luta, uma "peleja" de quatro despejos que a linguagem jurídica denomina de reintegrações de posse, marcadas pela violência policial e a prisão de quatro trabalhadores. Finalmente, um Decreto Presidencial, de 25 de março de 1995 desapropriou a Fazenda Modelo/Nazaré para fins de reforma agrária e em 17 de julho do mesmo ano ocorreu a imissão de posse.

3 "beiju" é um bolo feito com massa de mandioca, comum em comunidades rurais do Mato Grande e no litoral potiguar.

$4 \bigcirc$ Fausto, obra do escritor alemão Goethe, expressa e dramatiza o processo que se gesta em fins do século XVIII e início do seguinte pelo qual um tipo específico de modernidade emerge, movido pelas ideias de que o único meio de que dispõe o homem moderno para a sua própria transformação é a radical transformação de todo o mundo físico, moral e social em que ele está inserido. "Porém" - antecipa Berman (1986, p. 42) - "[...] o grande desenvolvimento que ele inicia - intelectual, moral, econômico, social - representa um altíssimo custo para o ser humano. Esse é o sentido da relação de Fausto com o diabo: os poderes humanos só podem se desenvolver através daquilo que Marx chama de 'os poderes ocultos', negras e aterradoras energias, que podem irromper com força tremenda, para além do controle humano. O Fausto de Goethe é a primeira e ainda a melhor tragédia do desenvolvimento."

\section{Referências}

BERMAN, Marshall. Tudo que é sólido desmancha no ar. São Paulo: Companhia das Letras, 1986.

BOURDIEU, Pierre. A dominação masculina. Rio de Janeiro: Bertrand Brasil, 2002. 
BRANDÃO, Carlos Rodrigues. O trabalho de saber. Porto Alegre: Sulina, 1999.

BRASIL. MINISTÉRIO DO PLANEJAMENTO. INSTITUTO BRASILEIRO DE GEOGRAFIA E ESTATÍSTICAS. Censo Demográfico $\mathbf{2 0 1 0}$ - características da população e dos domicílios resultados do universo. Rio de Janeiro, 2011.

DOMINGOS SOBRINHO, Moisés. "Habitus" e Representações Sociais: questões para o estudo de identidades coletivas. In: MOREIRA, Antonia Silva Paredes; OLIVEIRA, Denize Cristina (Org.) Estudos interdisciplinares de representação social. 2. ed. Goiânia: AB Editora, 2000.

DONA DAMIANA DE MELO. Entrevista. Assentamento Modelo, João Câmara (Rio Grande do Norte), 3 mar. 2005.

DONA MARIA CONCEIÇÃO MELO. Entrevista. Assentamento Modelo, João Câmara (Rio Grande do Norte), 25 jan. 2005.

DONA MARIA LÚCIA PEREIRA BARRETO. Entrevista. Assentamento Modelo, João Câmara (Rio Grande do Norte), 7 mar. 2005.

DONA RITA FERNANDES DA SILVA. Entrevista. Assentamento Modelo, João Câmara (Rio Grande do Norte), 24 jan. 2005.

ELOMAR. Cantiga de Estradar. Cantoria 1. Salvador: Kuarup Produção Fonográfica, 1984.

ESQUIVEL, Laura. Como água para chocolate. Rio de Janeiro/São Paulo: Record, 1995.

FRANCISCO DE ASSIS SIIVA (SEU PITIU). Entrevista. Assentamento Modelo, João Câmara (Rio Grande do Norte), 24 jan. 2005.

GARCIA JÚNIOR, Afrânio Raul. Terra de trabalho - trabalho familiar de pequenos produtores. São Paulo: Paz e Terra, 1983.

KENSKY, Vani. Memória e ensino. Cadernos de Pesquisa, São Paulo, n. 90, p. 45-51, ago. 1994.

LARROSA, Jorge. Tecnologias do eu e educação. In: SILVA, Tomaz Tadeu. O sujeito da educação. Petrópolis: Vozes, 1994.

MADEIRA, Margot Campos. Um aprender do viver: educação e representação social. In: MOREIRA, Antonia Silva P.; OLIVEIRA, Denize C. (Org.) Estudos interdisciplinares de representação social. 2. ed. Goiânia: AB Editora, 2000. 
MARTINS, José de Souza. O Sujeito oculto. Porto Alegre: Editora da UFRGS, 2003.

MORIN, Edgar. Os sete saberes necessários à educação do futuro. São Paulo: Cortez, Brasília (DF): UNESCO, 2000.

MOSCOVICl, Serge. A representação social da psicanálise. Rio de Janeiro: Zahar, 1978.

SEU EDUARDO MARCELINO DOS SANTOS, Entrevista. Assentamento Modelo, João Câmara (Rio Grande do Norte). 3 nov. 2004.

SEU JOÃO MARIA GABRIEL. Entrevista. Assentamento Modelo, João Câmara (Rio Grande do Norte), 7 mar. 2005.

SEU MANOEL CíCERO BANDEIRA. Entrevista. Assentamento Modelo, João Câmara (Rio Grande do Norte), 3 nov. 2004.

SEU MANOEL RODRIGUES. Entrevista. Assentamento Modelo, João Câmara (Rio Grande do Norte), 20 jul. 2004.

SEU PEDRO BARRETO DA SILVA. Entrevista. Assentamento Modelo, João Câmara (Rio Grande do Norte), 3 nov. 2004.

232 SEU RAIMUNDO ROSA. Entrevista. Assentamento Modelo, João Câmara (Rio Grande do Norte), 4 abr. 2005.

SÁ, Celso Pereira de. Núcleo central das representações sociais. 2. ed. Petrópolis: Vozes, 2002

SACRISTÁN, Jose Gimeno. A educação obrigatória. Porto Alegre: Artmed, 2001.

SIGAUD, Lígia. A Idealização do passado numa área de plantation. Contraponto. Rio de Janeiro, 1977.

SIIVA, Paulo Roberto Palhano. Novo momento da luta pela terra: quando o patrão sai de cena. 1996. 263f. Dissertação (Mestrado em Ciências Sociais) - Programa de PósGraduação em Ciências Sociais. Universidade Federal do Rio Grande do Norte, Natal, 1996. 
Dr. Alessandro Augusto de Azevêdo

Universidade Federal do Rio Grande do Norte Departamento de Práticas Educacionais e Currículo Grupo de Pesquisa Dialogicidade, Educação de Jovens e Adultos e Práticas Culturais E-mail | alessandroazevedo.ufrn@gmail.com

Recebido 27 dez. 2013 Aceito 15 jan. 2014 